\title{
The Plasma Environment of Comets
}

\author{
TAMAS I. GOMBOSI
}

\author{
Department of Atmospheric, Oceanic and Space Sciences, Space Physics Research Laboratory, \\ The University of Michigan, Ann Arbor
}

\begin{abstract}
This review concentrates on US research activities in the area of cometary plasma physics during the four year period from 1987 to 1990 . This quadrennium immediately followed the historic "traffic jam" on the dusty roads of Giacobini-Zinner and Halley; during this period there has been a substantial increase of activity in the area of cometary science. During these years the "comet rush" resulted in a better understanding of the major physical and chemical processes controlling cometary environments. The quantitative and qualitative leap of available information paved the road to a new generation of comprehensive models synthesizing our knowledge about the ionosphere, magnetosphere, and solar wind interaction. In spite of these major advances cometary plasma physics is still a rapidly changing - and sometimes controversial - subject, and one can can expect significant progress during the next quadrennium.
\end{abstract}

\section{INTRODUCTION}

The first results of the spectacular and highly successful missions to Comets Giacobini-Zinner and Halley were published shortly before the previous IUGG meeting in several special publications (Science, vol.232, pp 353-385, 1986; Nature, vol. 321, pp 259-366, 1986; Exploration of Halley's Comet, eds. B. Battrick, E.J. Rolfe, R. Reinhard, ESA-SP-250, 1986), but most of the detailed data analysis, interpretation and model development has been carried out during the present quadrennium. These four years were also characterized by the development of a new generation of comprehensive cometary plasma environment models synthesizing extensive ground based and in situ observations.

It was recognized about a quarter century ago [Biermann et al., 1967] that the expanding cometary exosphere represents an extensive, "soft" obstacle for the supersonic and superAlfvénic solar wind flow. The resulting interaction is very different from that with other solar system bodies with gravitationally bound dense atmospheres and/or significant intrinsic magnetic fields. Neutral atoms and molecules of cometary origin become ionized (because of photoionization, charge transfer or electron impact ionization) with characteristic ionization scale lengths of $10^{5}-10^{7} \mathrm{~km}$. The ionization process introduces a new, practically stationary particle into the high speed magnetized flow of the solar wind. Spacecraft instrumentation at comets Giacobini-Zinner and Halley detected large amplitude low frequency magnetic field fluctuations. These fluctuations grow from the relatively low solar wind turbulence level (at large cometocentric distances) to very large amplitudes in the vicinity of the bow shock. The enhanced fluctuation level is due to instabilities associated with the solar wind interaction with ionized cometary material.

In their pioneering work Biermann et al. [1967] assumed that the plasma flow rapidly accommodates the new ions, i.e. the entire plasma population can be characterized by a single temperature and flow velocity. Biermann et al. [1967] had also predicted that the deceleration of the solar wind flow by mass loading leads to the formation of a weak shock and the flow is impulsively decelerated to subsonic velocities. Later Galeev et

Copyright 1991 by the American Geophysical Union.

Paper number 91RG00752.

$8755-1209 / 91 / 91$ RG00752 $\$ 15.00$ al. [1985] recognized that implanted cometary ions carry most of the hydrodynamic pressure and that charge exchange cooling of the implanted plasma population can play a very important role in the dynamics of the contaminated solar wind flow. Their model predicted a weak and highly structured shock with a viscous subshock, a continuously decelerated and cooled plasma flow behind the shock and finally a stagnation region. The in situ measurements later confirmed the gross features predicted by this model.

Downstream of the bow shock the plasma population is a varying mixture of shocked plasma (solar wind contaminated with upstream pick-up particles) and cometary plasma ionized in the subsonic region. This region is called the cometosheath. The cometosheath is characterized by a rapidly increasing rate of ion pickup (as the plasma moves towards the comet), resulting in continuous deceleration (and eventual stagnation) of the plasma flow, accompanied by increasing plasma density and magnetic field magnitude. The inner, nearly stagnating region of the cometosheath is primarily photochemically controlled and the plasma density varies as $\mathbf{r}^{-1}$.

Our understanding of the main physical processes controlling the "ionopause" (the surface separating the magnetized cometosheath plasma from the magnetic field-free inner cometary ionosphere) was significantly modified by Giotto's encounter with comet Halley. The diamagnetic cavity boundary is formed at a location where the inward-pointing (towards the comet) total magnetic force (the sum of the magnetic pressure gradient and magnetic curvature forces) is balanced by the outward pointing ion-neutral drag force. Before the cometary encounters, an inner shock was predicted inside the "ionopause" to decelerate the supersonic outflow of the cometary ions and divert them toward the tail [Wallis and Dryer, 1976]. In reality, the drag by the rapidly expanding neutral gas forces the plasma to maintain supersonic velocity up to the immediate vicinity of the diamagnetic cavity boundary, where it undergoes a shock transition [Cravens, 1989b]. The shocked ionospheric plasma piles up, and is rapidly removed by recombination.

This review focuses on recent (1987-1990) US contributions to cometary plasma physics. Special attention will be given to models and observations that modified our pre-encounter understanding of cometary plasma environments. 


\section{MASS LOADING AND ITS CONSEQUENCES IN THE UPSTREAM REGION}

Our present, post-encounter understanding of cometary nuclei is based on Whipple's [1950] "dirty iceball" idea, which visualizes them as chunks of ice, rock, and dust with negligible surface gravity. As comets approach the sun, water vapor and other volatile gases sublimate from the surface layers generating a rapidly expanding dusty atmosphere. The sublimated gas molecules (often called parent molecules) undergo collisions and various fast photochemical processes in the near nucleus region, thus producing a whole chain of daughter atoms and molecules. There is growing evidence that dust grain photochemistry, as well as gas - dust chemical reactions also contribute to the generation of the observed atmospheric composition.

A well developed cometary atmosphere extends to distances some six orders of magnitude larger than the size of the nucleus. The dominant neutral molecules in this extended exosphere are $\mathrm{H}_{2} \mathrm{O}, \mathrm{CO}_{2}, \mathrm{CO}$ and their daughter products. Most of these neutral particles move with velocities of about $1 \mathrm{~km} / \mathrm{s}$ with respect to the cometary nucleus and with a velocity of about $-\vec{u}(\vec{u}=$ solar wind velocity) with respect to the plasma flow. Pickup of cometary particles, ionized by photoionization, charge exchange or electron impact, is the main physical process whereby comets interact with the solar wind.

Freshly bom ions are accelerated by the motional electric field of the high-speed solar wind flow. The ion trajectory is cycloidal, resulting from the superposition of gyration and $\overrightarrow{\mathrm{E}} \times \overrightarrow{\mathrm{B}}$ drift. The resulting velocity-space distribution is a ringbeam distribution, where the gyration speed of the ring is $v_{1}=u$ $\sin \alpha$, (where $u$ is the bulk plasma speed and $a$ is the angle between the solar wind velocity and magnetic field vectors) and the beam velocity (along the magnetic field line) is $v_{\| \mid}=u \cos \alpha$. The ring beam distribution has large velocity space gradients and it is unstable to the generation of low frequency transverse waves.

In the quasi-parallel regime $\left(\alpha \leq 60^{\circ}\right)$ the initial cometary ion velocity component parallel to the magnetic field exceeds the perpendicular velocity component. This situation typically results in the growth of electromagnetic ion/ion instabilities [Gary and Madland, 1988], especially the ion/ion right hand resonant instability, which has positive helicity and propagates parallel to the beam direction in the solar wind frame. These low frequency waves (which are sometimes called Alfven waves in the literature, even though strictly speaking they are not) are non-compressive, propagate near the Alfven speed $\left(V_{A}=B /\left(\mu_{0} \rho\right)^{1 / 2}, \rho\right.$ being the plasma mass density) and are in cyclotron resonance with the pickup ions themselves.

In the quasi-perpendicular regime $\left(60^{\circ} \leq \alpha \leq 90^{\circ}\right)$ the parallel velocity is smaller than the perpendicular one and the left-hand polarized electromagnetic ion-cyclotron instability becomes the dominant wave mode. There are two ion-cyclotron anisotropy instabilities: a positive helicity mode (which propagates antiparallel to the beam) and a negative helicity mode (which propagates parallel to the beam [Gary and Schriver, 1987]). In the limit of $\alpha=90^{\circ}$, these two instabilities grow at the same rate. The pickup-process-generated instabilities and their growth rates were discussed in a series of papers (cf. [Brince and Tsurutani, 1987a; Brinca and Tsurutani, 1987b; Brinca and Tsurutani, 1988a; Brinca and Tsurutani, 1988b; Brinca and Tsurutani, 1989a; Brinca and Tsurutani, 1989b; Brinca et al., 1989; Gaffey et al., 1988; Gary et al.,
1989; Gary and Madland, 1988; Gary et al., 1988; Gary and Omidi, 1987; Gary and Sinha, 1989; Goldstein et al., 1987b; Goldstein and Wong, 1987; Goldstein et al., 1990; Lee, 1989; Lee and Ip, 1987; Sagdeev et al., 1986; Thorne and Tsurutani, 1988; Winske et al., 1985; $W u$ and Davidson, 1972]).

Upstream of the shock, where the condition $V_{A} / u<<1$ is satisfied, the combination of ambient and self-generated magnetic field turbulence pitch-angle scatters each group of newborn ions from the pickup ring onto a spherical velocityspace shell of radius $u$, centered at the average wave phase velocity. The average wave velocity primarily depends on the angle $\alpha$. For quasiparallel configurations $\left(\alpha<60^{\circ}\right)$ the self generated waves primarily propagate in the direction of the ring-beam and only a few percent of the cometary turbulence propagates backward (toward the comet) [Miller et al., 1990a; Miller et al., 1990b]. In this case the ambient solar wind turbulence is an important contributor to the backward propagating waves and the average wave speed is somewhere between 0 and $V_{A}$ (see Figure 1). The wave field is quantitatively different in the quasiperpendicular case. When $\alpha>60^{\circ}$, an approximately equal number of the pickup generated waves moves along the ring-beam and toward the comet [Miller et al., 1990a; Miller et al., 1990b]. In this situation the average wave speed is approximately zero.

In the case of perpendicular pickup, particles pitch-angle scatter toward isotropy in the average wave frame, which practically coincides with the solar wind frame. In this situation the pickup particles are scattered on the spherical velocity space shell B (see Figure 1). In a first approximation the pickup particles interact with the low frequency waves without significantly changing their energy in the average wave frame. As a result of this process the pitch angles of the pickup-ring particles are scattered on the spherical velocity space shell of radius $u$ (see Figure 1) around the local solar wind velocity. Observations indicate that this process does not lead to pitch-angle isotropy until very close to the cometary shock [Coates et al., 1990a; Coates et al., 1989a; Coates et al., 1989b; Neugebauer et al., 1990a; Neugebauer et al., 1987a; Neugebauer et al., 1989b]. The reason is that in the upstream region the ion production rate increases exponentially and therefore the pickup ion population is dominated by the locally implanted particles, which did not have enough time to pitch-angle scatter toward isotropy. As one approaches the shock region the pitch-angle scattering time decreases, while

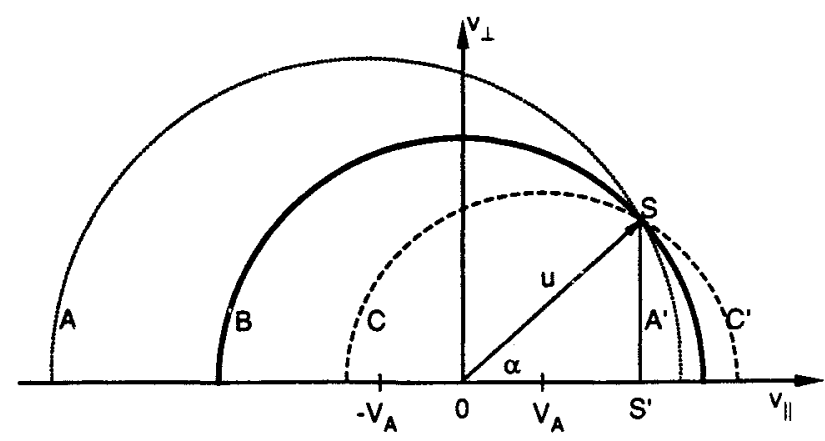

Fig, 1. Potential pitch-angle scattering path of implanted ions in the plasma frame. Here $\alpha$ is the angle between the solar wind velocity and magnetic field vectors, while $v_{\text {, }}$ and $v_{\text {, }}$ represent velocity components perpendicular and parallel to the magnetic field. $S$ marks the injection velocity of the freshly born particles and the line (SS') is the projection of the initial ring distribution to the $\left(v_{1}, v_{1 k}\right)$ plane. 
the ion production rate increases only as $\mathrm{r}^{2}$. The consequence of these changes is that in this region the bulk of the implanted ion population did have enough time to undergo considerable pitch-angle scattering, thus their distribution approaches isotropy.

The situation is quite different for quasiparallel geometries $\left(\alpha<60^{\circ}\right)$. In this case the pickup generated MHD turbulence propagates predominantly in the direction of the ring-beam. Pickup ring particles, which pitch-angle scatter on these fluctuations conserve their energy in the frame of the scattering turbulence; therefore, they populate a spherical shell centered around $\left(v_{\perp}=0, v_{\|}=V_{A}\right.$, where $v_{\perp}$ and $v_{\|}$represent velocity components perpendicular and parallel to the magnetic field, respectively) and going through the injection point, $S$. This shell is represented by the arcs $C$ and $C^{\prime}$ in Figure 1. At the same time there is ambient solar wind turbulence (and a small fraction of the pickup generated MHD waves), which propagates at the local Alfven speed along the magnetic field lines, and travels predominantly away from the sun. In the coordinate system of Figure 1 this turbulence is represented by the $v_{\perp}=0, v_{\|}=-V_{A}$ point. Pickup ring particles scattered on these waves populate a spherical shell centered around $v_{1}=0, v_{\|}=-v_{A}$ and going through the injection point, $S$. This shell is marked in Figure 1 by the arcs $A$ and $A^{\prime}$. It was first suggested by Galeev and Sagdeev [1988] that in the case when the energy densities of parallel and antiparallel propagating Alfven waves are more or less identical, the two lower energy branches (in the plasma frame of reference) are most likely to be populated, since a large fraction of the wave energy comes from the ions, which therefore lose energy. This model predicts a bispherical distribution, with particles distributed along the branches $A^{\prime}$ (centered on $-V_{A}$ ) and $C$ (centered on $V_{A}$ ). The bulk speed of the bispherical distribution is moved from the solar wind velocity to a velocity parallel to the injection ring beam.

Implanted ions were detected at comets Giacobini-Zinner and Halley [Hynds et al., 1986; Ipavich et al., 1986; Kecskeméty et al., 1989; McKenna-Lawlor et al., 1989; McKenna-Lawlor et al., 1986; Somogyi et al., 1986] as large fluxes of energetic particles. A significant part of the detected energetic ion population was observed at energies considerably larger than the pickup energy, indicating the presence of some kind of acceleration process acting on implanted ions. Velocity diffusion of lower energy implanted ions (near the pickup energy) has also been observed by several instruments upstream of the Comet Halley bow shock [Coates et al., 1989b; Neugebauer et al., 1989b]. The acceleration of the implanted ions in the cometary upstream region has also generated considerable theoretical interest. This problem was first examined just before the Giacobini-Zinner encounter [Amata and Formisano, 1985]. In a subsequent paper written shortly before the Halley encounters, Ip and Axford [1986] considered five potential mechanisms that can act to accelerate implanted ions. They concluded that in cometary environments the second-order Fermi acceleration (slow velocity diffusion due to the interaction with propagating Alfven waves) was likely to play a dominant role in accelerating ions of cometary origin far upstream from the comets. Later Isenberg [1987a] published an elegant analytic solution for a specific scenario, which took into account convection, adiabatic acceleration and velocity diffusion. It was assumed that the implanted cometary particles were scattered between self-generated waves (propagating towards

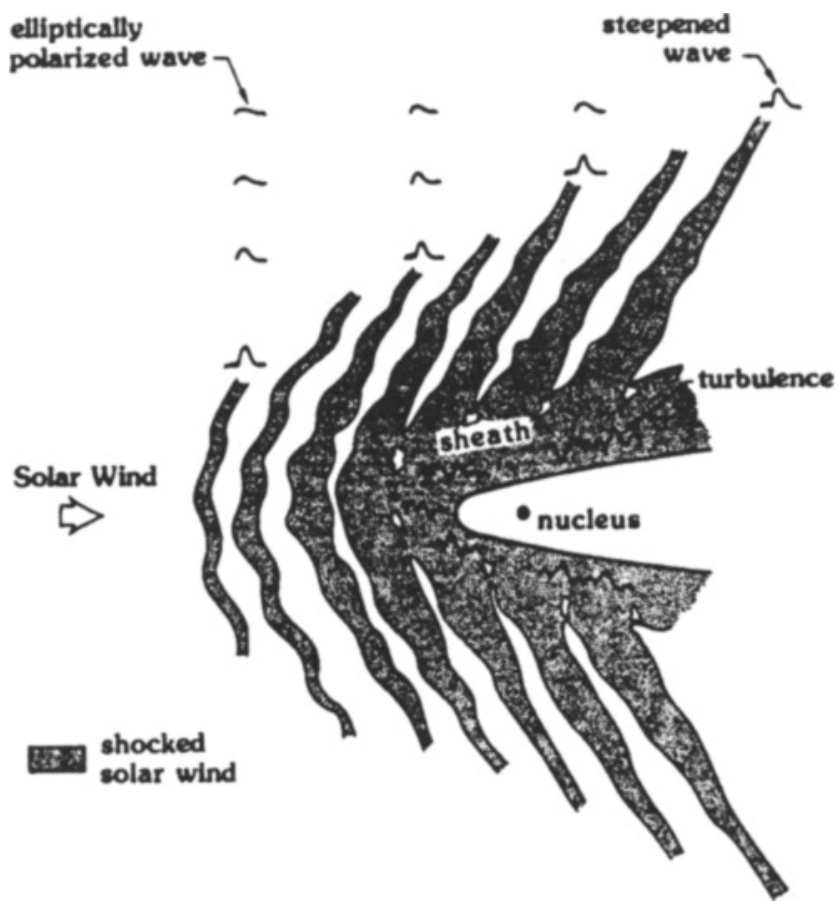

Fig. 2. A schematic representation of the formation of multiple shocklets [Omidi and Winske, 1990a].

the sun) and pre-existing waves in the solar wind (predominantly propagating away from the sun). In order to be able to obtain an analytic solution Isenberg had to make a number of simplifying assumptions; nevertheless this solution represents a major step towards self-consistent modeling of the upstream-region acceleration of implanted cometary ions.

Shortly after Isenberg's analytic solution Gombosi, [1988a] developed a self-consistent, three-fluid model of plasma transport and implanted ion acceleration in the unshocked solar wind. In this model the solar wind plasma (assumed to contain only protons and electrons) was depleted by charge exchange with the expanding cometary exosphere, while implanted protons and heavy ions (mainly $\mathrm{O}^{+}$) were produced by photoionization and charge transfer and lost by charge exchange. A generalized transport equation describing convection, adiabatic and diffusive velocity change, and the appropriate production terms, was used to describe the evolution of the two cometary ion components, while the moments of the Boltzmann equation were used to calculate the solar wind density and pressure. This model has recently been extended to include the effects of first-order Fermi acceleration [Gombosi et al., 1989]. In this new model a modified scenario was suggested in which a second-order Fermi mechanism accelerates ions to moderate energies in the cometary upstream region and then in the foreshock region (where the solar wind slows down from its ambient speed to about 0.8 times its upstream value [Coates et al., 1987]) the superthermal implanted ions are further energized by a diffusive-compressive shock acceleration process (first-order Fermi acceleration) [Gombosi et al., 1989].

\section{THE COMETARY SHOCK}

A newly born cometary ion is initially almost at rest, but is subsequently accelerated by the motional electric field of the streaming solar wind. Photoionization and electron impact ionization result in the addition of plasma to the contaminated 
solar wind, while charge exchange replaces a fast ion with an almost stationary one. It should be noted that at large cometocentric distances the two dominant cometary neutral species are $\mathrm{H}$ and $\mathrm{O}$ atoms, which both have large, resonant charge exchange cross sections with protons, which represent the vast majority of solar wind particles. The $\mathrm{H}^{+}+\mathrm{O} \rightarrow \mathrm{H}+\mathrm{O}^{+}$ reaction also adds mass (but not charge) to the plasma. Conservation of momentum requires that the solar wind be decelerated as newly born charged particles are "picked up" by the plasma flow. This effect was first modeled by Biermann et al., [1967], who assumed that the plasma flow rapidly accommodates the newly born cometary ions, i.e. the entire plasma population can be characterized by a single temperature and flow velocity. This assumption made it possible to apply a single-fluid hydrodynamic treatment to the continuously mass loaded plasma flow and to use the conservation equations to describe the deceleration of the contaminated solar wind flow. Biermann et al. [1967] had also shown that continuous deceleration of the solar wind flow by mass loading is possible only up to a certain point at which the mean molecular weight of the plasma particles reaches a critical value. At this point a weak shock forms and impulsively decelerates the flow to subsonic velocities.

Wallis and Ong [1975] were the first to recognize that implanted cometary ions do not accommodate to the solar wind flow; therefore the application of a single-fluid hydrodynamic treatment was unjustified. By assuming that the flow velocity was perpendicular to the magnetic field direction and that the first adiabatic invariant of cometary ions was conserved, they were able to determine the implanted particle distribution function and combine it with the magnetohydrodynamic equations to obtain the contaminated solar wind flow parameters. In a subsequent calculation, Galeev et al. [1985] recognized that implanted cometary ions carry most of the hydrodynamic pressure and that charge exchange cooling of the implanted plasma population can play a very important role in the dynamics of the contaminated solar wind flow. In this calculation, generalized transport equations were applied to describe the continuously contaminated plasma flow along the subsolar line. The model predicted a weak and highly structured shock with a viscous subshock, a continuously decelerated and cooled plasma flow behind the shock and finally a stagnation region.

Bow shock crossings were identified in the data from each of the Halley flyby spacecraft at approximately the expected locations. The shock jumps were clearly defined in many of the observations from the plasma probes and magnetometers on Giotto, VEGA and Suisei. For Giacobini-Zinner it is generally recognized that the pickup ions generated so much mass loading and turbulence that the shock crossing was extremely thick and difficult to identify. The detailed physical reason for the differences is still the subject of debate. The cometary "shock wave" is quite different than the "classical" planetary and interplanetary shocks, because the deceleration and dissipation is due to mass loading and wave-particle interaction and they take place over a very large region with the "shock" being only the downstream boundary of an extended distributed process. Omidi and Winske suggest that the concept of a single bow shock should be replaced by a series of relatively weak shocklets that evolve from steepened magnetosonic waves [Omidi and Winske, 1988; Omidi and Winske, 1990a; Omidi and Winske, 1990b]. These authors carried out a twostep plasma simulation: first a large system was used to generate a series of kinetic magnetosonic waves via the resonant electromagnetic ion-beam instability, while in the second step one of these was isolated and its non-linear evolution was investigated in a smaller periodic box. These simulations clearly show the development of steepened magnetosonic waves, which are localized shock waves, termed shocklets [Omidi and Winske, 1988; Omidi and Winske, 1990a; Omidi and Winske, 1990b]. The shocklets move with a velocity of 2-3 $\mathrm{V}_{\mathrm{A}}$ towards the sun (in the plasma frame of reference), but in the cometary frame they are transported downstream, consequently, they can not form a standing "planetary" shock upstream of the comet. Omidi and Winske concluded that the solar wind is not shocked by a single standing shock, but by a series of localized, downstreamtransported shocklets [Omidi and Winske, 1988; Omidi and Winske, 1990a; Omidi and Winske, 1990b]. It was pointed out by Neugebauer [1990] that the magnetic profiles of Omidi and Winske's shocklets are strikingly similar to the steepened magnetosonic waves observed at Giacobini-Zinner [Tsurutani et al., 1987b].

\section{From THE SHOCK to THE DLAMAGNETIC CAVTTY: THE COMETOSHEATH}

The cometosheath is located between the cometary shock and the magnetic field free region in the innermost coma. The plasma population in the cometosheath is a changing mixture of ambient solar wind and particles picked up upstream and downstream of the shock. The distinction between cometary particles picked up outside and inside the shock is important because of the large difference in their random energy. The random energy of ions in a pickup shell is typically $20 \mathrm{keV}$ for $\mathrm{O}^{+}$ions picked up upstream of the shock. Cometary ions born behind the shock are picked up at smaller values of $u$, and consequently, the random energy of their pickup shell is significantly smaller than that of ions born upstream of the shock. Overall ions retain (in their energy) a memory of where they were born, and the plasma frame energy of pickup ions decreases with decreasing cometocentric distance. The observed distribution functions are complicated, but behind the shock they become quite isotropic [Coates et al., 1990a; Coates et al., 1989b; Neugebauer, 1990; Neugebauer et al., 1989b].

The cometosheath is one of the most interesting and controversial regions of the cometary plasma environment. This fact is not surprising because several independent measurements were carried out in this region, but the temporal and spatial extent of the observations were limited enough to leave plenty of room for different interpretations.

One of the debated issues is whether or not energetic electrons are a permanent feature of the cometosheath. The electron spectrometer on Giotto observed large fluxes of energetic (0.8-3.6 keV) electrons in the so called "mystery region" between about $8.5 \times 10^{5}$ and $5.5 \times 10^{5} \mathrm{~km}$ [Reme, 1990]. At a cometocentric distance of about $5.5 \times 10^{5} \mathrm{~km}$ these fluxes abruptly disappeared, simuitaneously with a sudden decrease of the total ion density and velocity and an increase of the ion temperature. At the same time the magnetic field changed direction and became much smoother. Reme interpreted this change as a permanent feature of the cometosheath and found similar events in the Vega and Suisei data sets [Reme, 1990]. A different view was presented by Gringauz and Verigin [1990], who did not see evidence of the presence of energetic electrons in the cometosheath and interpret the Giotto energetic electron 
event as a transient feature generated by a passing interplanetary disturbance.

Another subject where different opinions exist is the collisionopause. Near the shock the plasma is practically collisionless, but collisions become more and more important as one approaches the inner regions of the cometosheath, because both the neutral gas and plasma densities increase and the plasma flow velocity decreases. One definition of the collisionopause was given by Mendis et al., [1986], who defined it as the boundary where the mean free path of the ionneutral momentum transfer collisions equals to the cometocentric distance. On the other hand there are many kinds of different collisions, such as charge exchange, elastic electron-ion and ion-neutral, electron impact ionization, ionneutral chemistry; and the collisionopause for every single process will be located at different cometocentric distances [Cravens, 1989a; Cravens, 1990a]. Cravens defines the collisionopause for a given collisional process as the boundary where the characteristic transport time $\left(\tau_{\mathrm{T}}\right)$ of the plasma is equal to the characteristic collision time $\left(\tau_{C}\right)$ for the given process [Cravens, 1989a]. Cravens estimates that the ion-neutral charge transfer collisionopause is located at about $1.5 \times 10^{5} \mathrm{~km}$, while the collisionopause of $\mathrm{H}_{2} \mathrm{O}^{+}$(due to ionneutral chemistry) is located at about $4 \times 10^{4} \mathrm{~km}$ [Cravens, 1989a].

Another very interesting feature in the cometosheath is the cometopause, discovered by the Vega plasma instrument [Gringauz et al., 1986a; Gringauz et al., 1986b]. At around $1.65 \times 10^{5} \mathrm{~km}$ the PLASMAG instrument observed a sharp transition from a primarily solar wind proton dominated plasma population to a mainly cometary water group ion plasma. This transition was also accompanied by a moderate increase in the low frequency plasma wave intensity, while there were no obvious changes in the magnetic field [Galeev et al., 1988]. The plasma instrument on Giotto also observed a plasma boundary at about $1.35 \times 10^{5} \mathrm{~km}$ cometocentric distance. However, there were important differences between the Vega and Giotto observations. As summarized by Neugebauer, [1990], the Giotto magnetometer observed an increase of the magnetic field magnitude by about a factor of 4 [Neubauer et al., 1986], accompanied by a decrease of electron density and a change in the angular distribution of electrons from nearly isotropic to strongly anisotropic [d'Uston et al., 1989]. The ion composition changed from solar wind protons to primarily cometary water group ions, but the transition was much broader than either the magnetic discontinuity observed by Giotto or the cometopause observed by Vega [Neugebauer, 1990]. The unexpected feature of the cometopause was not its existence (a gradual transition from solar wind dominated plasma flow to a heavily contaminated, pick-up ion dominated plasma was predicted by several theoretical models [Galeev et al., 1985; Mendis et al., 1985]), but its sharpness. It should be mentioned that some scientists question the existance of the cometopause: they argue that this structure is probably the result of passing interplanetary discontinuities [Reme, 1990].

Several theoretical models were suggested to explain the physics of the cometopause. The models can be divided into two broad categories: collective and collisional. Collective models explain the transition by some kind of resonant interaction. Galeev et al., [1988] suggested that at the cometopause the firehose instability is excited by the velocity differerice between the fast solar wind protons and slower cometary ions. This instability can result in a collisionless deceleration of the protons and a simultaneous isotropization of the proton distribution function. Outside of the cometopause cometary implanted ions gyrate around the magnetic field carried by the solar wind protons, while inside the cometopause the field is carried by cometary ions and the solar wind protons gyrate around the field. This means that the plasma detector pointing to the ram direction will see an abrupt increase in the number of detected cometary ions and a simultaneous decrease in the number of detected protons [Galeev et al., 1988]. Another plasmaphysical model is a 1D multifluid MHD description, allowing for different solar wind proton and implanted ion flow velocities. In this model the flow decelerates near $10^{5} \mathrm{~km}$, where the flow speed and the proton Alfven speed are equal, indicating the presence of some kind of resonant interaction [Sauer et al., 1990].

One of the collisional models considers the cometopause to be a boundary where enhanced momentum transfer with the outflowing neutrals decelerate the inflowing contaminated solar wind [Flammer, 1990; Mendis et al., 1989]. In this model the cometocentric distance of the cometopause (along the sun-comet line) is obtained by simply equating the momentum transfer mean free path with the radial distance from the nucleus. Another collisional model, which is capable of explaining the sharp transition at the cometopause, was put forward by Gombosi [1987], who suggested that an "avalanche" of charge exchange collisions in the decelerating plasma flow can rapidly deplete the solar wind proton population and replace it with slower water group ions. In order to illustrate this process, Gombosi [1987] published a one-dimensional analytic solution to the multispecies transport equations (valid along the sun-comet line). Later Ip [1989] extended Gombosi's [1987] model to two dimensions using the flow field generated by a 3D MHD model [Fedder et al., 1986]. Figure 3 shows a comparison of Ip's calculations with the Giotto observations. Inspection of Figure 3 shows a good general agreement for water group ions, but shows solar wind protons penetrate further into the coma than expected. This discrepancy might be due to somewhat incorrect aeronomic parameters (the charge exchange cross sections are not well known) or to the neglect of magnetic field effects (after all, observations also show the presence of a magnetic discontinuity). It should be noted that magnetic field effects were included in the 3D MHD model of Wegmann et al., [1987], which also incorporated detailed chemistry. However, the Wegmann et al. [1987] calculation had only a limited spatial resolution in the vicinity of the cometopause.

Inside the cometopause ion-neutral chemistry and recombination starts to become more and more important. Inside the collisionopause of the dominant process controlling a particular species, photochemistry dominates. For instance, the collisionopauses of the $\mathrm{H}_{2} \mathrm{O}^{+}$and $\mathrm{H}_{3} \mathrm{O}^{+}$ions are located at about $4 \times 10^{4} \mathrm{~km}$ and $2 \times 10^{4} \mathrm{~km}$, respectively [Cravens, 1989a; Cravens, 1990a]. Inside these boundaries the net production rates of the $\mathrm{H}_{2} \mathrm{O}^{+}$and $\mathrm{H}_{3} \mathrm{O}^{+}$ions are nearly zero (i.e., production equals loss everywhere). For instance, $\mathrm{H}_{3} \mathrm{O}^{+}$is produced by the $\mathrm{H}_{2} \mathrm{O}^{+}+\mathrm{H}_{2} \mathrm{O} \rightarrow \mathrm{H}_{3} \mathrm{O}^{+}+\mathrm{OH}$ reaction and is lost by dissociative recombination, $\mathrm{H}_{3} \mathrm{O}^{+}+\mathrm{e} \rightarrow \mathrm{H}_{2} \mathrm{O}+\mathrm{H}$. Inside the $\mathrm{H}_{3} \mathrm{O}^{+}$collisionopause the major ion is $\mathrm{H}_{3} \mathrm{O}^{+}$, consequently the electron density can be obtained by equating the production and loss rates. The resulting electron density is inversely proportional to the cometocentric distance and proportional to $\mathrm{T}_{\mathrm{c}}^{1 / 4}$ (cf. [Cravens, 1989a; Cravens, 1990a; Ip et al., 1987]). This result was experimentally verified by the Giotto ion mass 

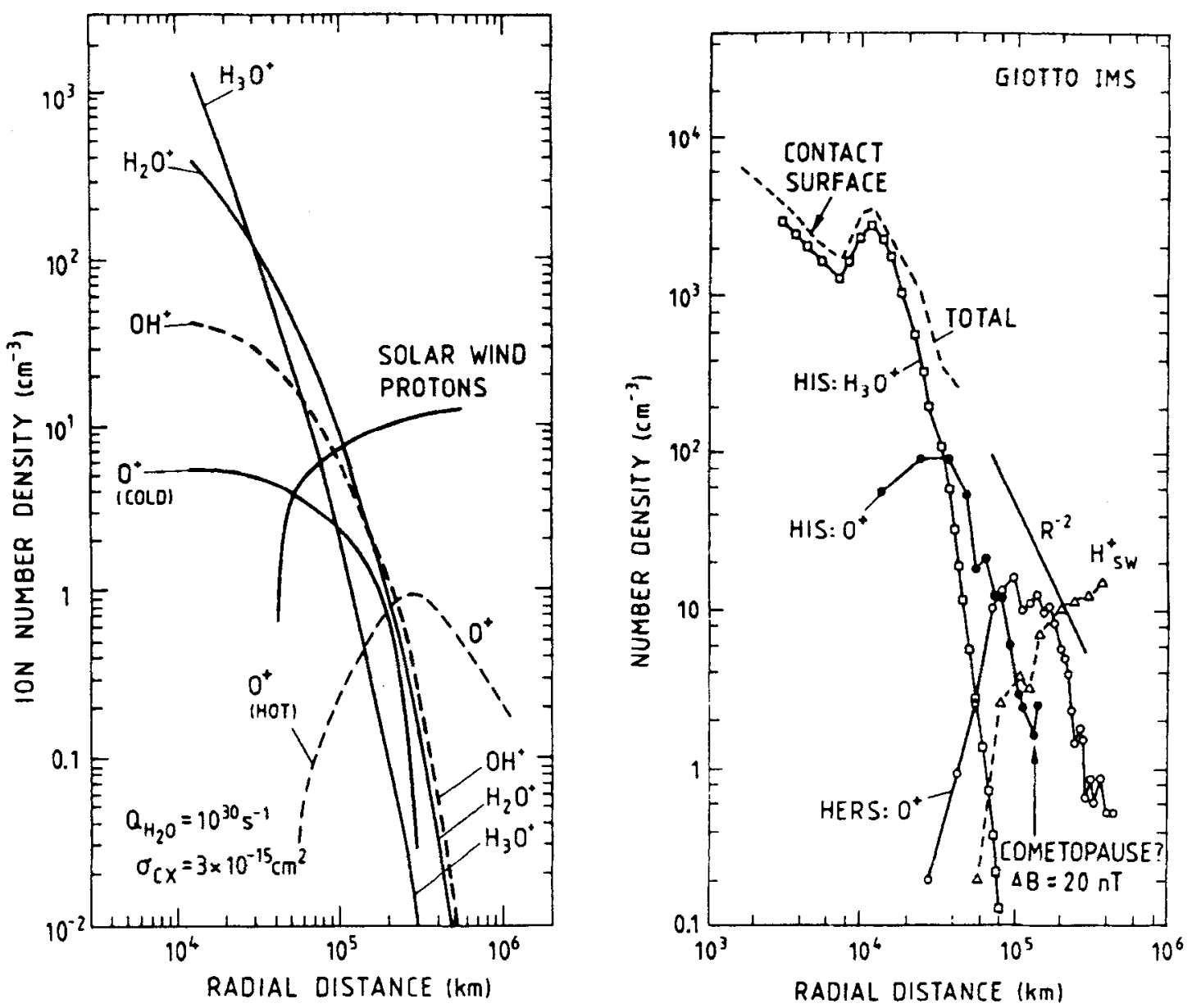

Fig. 3. The calculated (left panel) and observed (night panel) cometocentric variation of ion densities along the inbound Giotto trajectory. (Taken from $I p,[1989]$.

spectrometer [Balsiger et al., 1987; Balsiger et al., 1986]. It should also be pointed out that uncertainties of many of the important cross sections and reaction rates make realistic modeling of most collisional processes quite difficult.

In the collision dominated inner region the energetics of ions and electrons is controlled by local processes, such as photochemical and collisional heating. Due to the very strong ion-neutral coupling the ion temperature in this region is mainly determined by the neutral temperature with corrections due to photechemical heating (resulting in about a $100 \mathrm{~K}$ increase) and ion-neutral frictional heating [Cravens, 1987; Haerendel, 1987].

Electrons outside the stagnation region are basically of solar wind origin, while in the dense inner coma the electron distribution is greatly modified by collisions and with the addition of a photoelectron population. Several theoretical models were published to describe this changing electron distribution [Gan and Cravens, 1990; Körösmezey et al., 1987]. These models consider two electron populations: a cold and dense component $\left(n_{e}-10^{3}-10^{4} \mathrm{~cm}^{-3}, T_{e}<1 \mathrm{eV}\right)$, and an energetic photoelectron population. The photoelectrons heat the colder thermal population via Coulomb collisions.

\section{The DIAMagnetIC CaVtTY BOUNDARY AND THE INNER SHOCK}

Before the Giotto encounter there was a vigorous debate in the literature about the existence and nature of the "ionopause" or "contact surface", separating the mixed, solar wind controlled magnetized plasma from the magnetic field free, cometary ionosphere (for an excellent pre-encounter review see [Mendis et al., 1985]). At a cometocentric distance of about $4600 \mathrm{~km}$ the Giotto magnetometer detected a very sharp drop of the magnetic field magnitude from about $60 \mathrm{nT}$ to practically zero [Neubauer et al., 1986]. Behind this boundary the spacecraft entered into a magnetic field free region, the diamagnetic cavity. The inner edge of the diamagnetic cavity boundary was very thin: the field decresed from $20 \mathrm{nT}$ to zero within about $25 \mathrm{~km}$ [Neubauer, 1988].

There is a debate going on in the cometary plasma physics community about the terminology to be used for this boundary. Some people prefer the term "ionopause", indicating that this boundary separates the solar wind controlled outer region from the inner one, entirely controlled by cometary dynamics. On the other hand the cometary "ionosphere", the photochemically controlled region, extends to the $\mathrm{H}_{3} \mathrm{O}^{+}$ collisionopause, located beyond $10^{4} \mathrm{~km}$ from the nucleus. The correct (but not widely used) terminology should be "diamagnetic cavity boundary" (DCB), as suggested by Cravens [1989b].

The observations have led to a series of new theoretical studies of the DCB discontinuity [Cravens, 1986; Cravens, 1989b; Eviatar and Goldstein, 1988; Flammer et al., 1990b; Haerendel, 1987; Ip et al., 1987]. It has been recognized shortly after the Giotto encounter that the dominant factor leading to the formation of DCB is the balance between the outward ion-neutral frictional force and the inward pointing 
J $\times B$ force (which is a combination of the magnetic pressure gradient and the curvature forces) [Cravens, 1986; Ip et al., 1987].

Deep inside the diamagnetic cavity the cometary plasma and the neutral gas are very strongly coupled by ion-neutral collisions, and they move radially outward with the same expansion velocity. Outside the cavity the plasma is nearly stagnated (it slowly flows around the DCB). Some ten years before the comet encounters Wallis and Dryer [1976] considered the interaction of the solar wind with a point-like supersonic plasma source, representing the comet, and predicted the formation of an inner shock well inside the contact surface. This inner shock was assumed to decelerate the supersonic cometary ion outflow to subsonic velocities and divert the flow towards the plasma tail. On the other hand, plasma instruments on Giotto did not see any signs of a shock inside the diamagnetic cavity, but detected supersonic outward flow of cometary ions right up to the diamagnetic cavity boundary (cf. [Neugebauer, 1990]). The observations clearly disagree with the prediction of the Wallis and Dryer [1976] model and one has to ask the question: what happens to the outflowing cometary ions at the DCB?

This question has recently been addressed using a one dimensional MHD calculation [Cravens, 1989b], who considered the physical processes in the thin layer $(-50 \mathrm{~km}$ wide) between the stagnated plasma on the outside and outflowing plasma on the inside. In the inner part of the transition layer the outflow velocity drops to practically zero from its supersonic value, while the thermal pressure and the particle density increase in order to keep the total pressure constant. In the outer part of the layer the density (and the pressure) decreases because the large number of low speed electrons and ions easily recombine. On the other hand the total pressure remains constant throughout the entire transition layer; therefore, an increase in the magnetic pressure compensates for the decreased thermal pressure in the outer part of the layer. Eventually all plasma entering the transition layer from the diamagnetic cavity is consumed by recombination inside the boundary layer, which truly separates the cometary plasma flow from the stagnated solar wind controlled outside flow [Cravens, 1989b]. This means that the inner shock is very close $(\sim 50 \mathrm{~km})$ to the DCB, and there is a thin density spike between the shock and the diamagnetic cavity boundary. Recently, a very high resolution analysis of the Giotto ion mass spectrometer data confirmed the existence of the density enhancement [Goldstein et al., 1989].

\section{The Plasma TaIL}

One of the very interesting and so far underexplored cometary regions is the plasma tail. The long, narrow plasma tail is one of the most visible cometary phenomena, and tails have been observed from earth orbit for a very long time. However, remote observations have only a very limited ability to provide information about such fundamental plasma features as magnetic field configuration, collective phenomena or reconnection.

In September 1985 the International Cometary Explorer (ICE) flew through the inner tail of comet Giacobini-Zinner. The general magnetic field configuration in the tail was quite similar to the draped field model put forward by Alfven [Alfuen, 1957]. The ICE spacecraft observed two tail lobes with magnetic field magnitudes around $60 \mathrm{nT}$ [Slavin et al., 1986]; these lobes were separated by a very thin layer of cold and dense plasma [Meyer-Vernet et al., 1986].

An extensively studied plasma tail phenomenon has been the occasional disconnection of cometary plasma tails. Niedner and Brandt, [1978] suggested that interplanetary sector boundary crossings are responsible for the disconnection of cometary plasma tails. Competing models assume that high speed corotating interaction regions (and not necessarily sector boundaries) trigger the tail disconnection, or that the phenomenon can be explained in terms of complicated cometary plasma processes [Jockers, 1985; Russell et al., 1986]. Based on simultaneous ground-based observations and information from the Vega magnetometer Niedner and Schwingenschuh published evidence for an interplanetary sector boundary triggered disconnection event [Niedner and Schwingenschuh, 1987]. It is obvious that more information is needed to resolve this issue.

Acknowledgments. This work was supported by NASA grants NAGW-1366 and NAGW-2162. Illuminating discussions with Dis. T.E. Cravens, S.P. Gary, M.A. Lee and M. Neugebauer are also acknowledged.

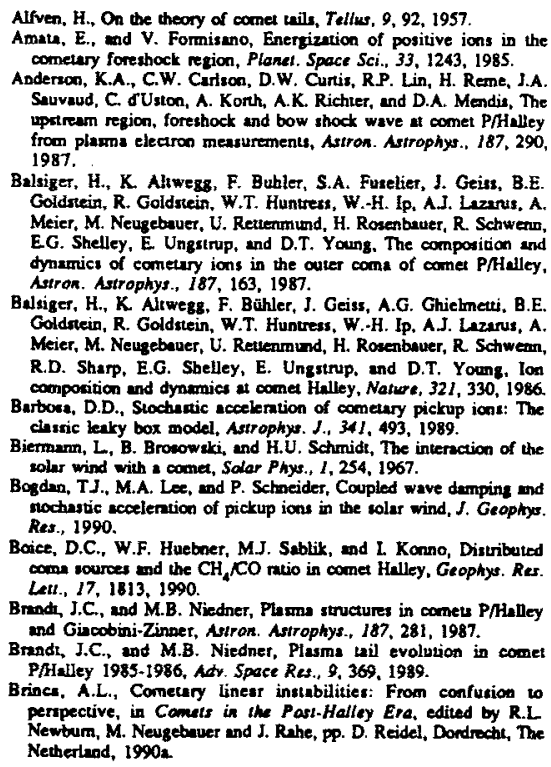

Aliven. H., On the theory of come wils, Tellus, 9, 92, 1957. $R P$. Sauvaud, C. GUston, A. Korth, A.K. Richter, and D.A. Mendis, The from plasma electron measurtements, Astron. Astrophys., 187, 290,

Ger, H., K Alwesg, F. Bubler, S.A. Fuselier, 1. Geiss, B.E.

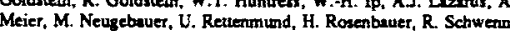
EG. Shelley, E. Ungsirup, and D.T. Young. The composicion and dynamics of comeury ions in the outer coma of comet P/Halley,
Astron. Astrophys., 187, 163, 1987. Balsiger, H., K Altwegs, F. Bühler, J. Geiss, A.G. Ghietmetri. B.E. Meier, M. Neugebeuct, U. Rettenmund, H. Rosenbouer, R Schwenn, R.D. Sharp, E.G. Shelley, E. Ungurup. and D.T. Young, Io Barbors, D.D., Stochantic accelerntion of comelary pickup ions: The cinsic leaky box model, Astrophys. J., 341, 493. 1989.

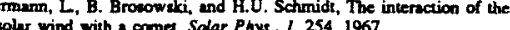
Gon, TJ., M.A. Lee, and P. Schneider, Coupled wave dempirs me Res., 1990

Bace, D.C., W.F. Huebner, M.J. Sablik, and I. Konno, Disuributed

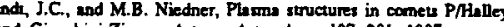
and Ginoobini-Zinnet, Attran. Astrophys., 187, 281, 1987. P/Falley 1985-1986, Ady. Space Res., 9. 369, 1989.

perspective, in Comets in the Past-Halley Era, codited by $R$ Netherland, 19902

Brinca, A.L., On the electromegnetic stubility of isotropic populations, J. Geophys. Res., 95, 221, $1990 \mathrm{~b}$

pancs, A.L, and B.T. Tsurntani, On the polstization, compression and onoscillatory behavior of hydromagnetic waves associated with pickup ion, Geophys. Res. Tell., I4, 495, 1987.

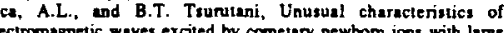
electromagnetic waves excited by cometury newbom ions with lare

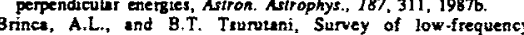
electronagnetic waves simulated by two coexisting newbom ion species, J. Geophys. Res., 93, 48, 1988 .

Brince, A.L. and B.T. Trunuteni, Temperature effeets on the pickup process of water-group and hydrogen ions: Extension of "A theory for low-frequency waves observed at comet Giecobini-Zinner" by M.L. Goldstein and H.K. Wong. J. Geophys. Res., 93, 243, 19880. Bninca, A.L., and B.T. Tsurutani, Influence of multiple ion species on low frequency ele

Brince, A.L. and B.T. Tsurveni, The oblique behevior of low-

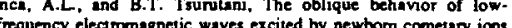
J. Geophys. Res., 94, 3, 1989b.

Brince, A.L., end B.T. Teurutani, On the excitution of erclaron hamonic waves by newborn heavy ions, J. Geophys. Res., 94. 5467, $1989 \mathrm{c}$.

Brinca, A.L. B.T. Tsuruteni, and F.L. Scarf, Local generation of electrostatic bursts at comet Giacobini-Zinner: Modulation by steepened magnetosonic waves, J. Geophys. Res., 94, 60, 1989. Brosius, I.W., G.D. Holman, M.B. Niedner. J.C. Brand, J.A. Slavin, E.J. Smith, R.D. Zwickl, and S.J. Bame. The caure of 1wo plasmatail disconnection events in comet P/Halley during the ICE-Halley
adial period, Astron. Astrophys., $187,267,1987$.

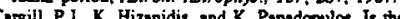

that". Th. Aizanidis, and X. Papadopulos, Is the comedery "bow hock" really a shock?, in Cometary and Solar Plasmo Physics. edied by B. Buti. pp. World Scientific. New York, 1988.

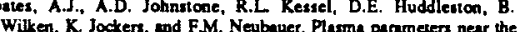
Wilken, X. Jockers, and F.M. Neubauer, Plasma parameeren near the
Contes, A.J., A.D. Johnstone, M.F. Thomsen. V. Formisano. E Amats, B. Wilken, $K$ Jockers, J.D. Winningham, H. Borg, and D. A. Bryant, Solar wind flow through the comet P/Halley bow shock
Astron. Astrophys., 187, 55, 1987. Contes, A J., A.D. Johnstone, B. Wilken, K. Jockers, and K.H. Glassmeier, Correction to "Velociry space diffusion of pickup ion from the water group at comel Helley", J. Geophys. Res., 95, 4343, from Costet, A.1., A.D. Johnstone, B. Wikken, K. Jockers, and K.H.
Glassmeier, Velocity-space diffusion of pickup ions from water group at Comea Halley. J Geophys. Res., 94, 9983, 1989b.

Coates, A.J., A.D. Johnstone, B. Wilken, K. Jockers, end X.H Glassmeier, Velocity-spece diffusion of pickup ions from water group at Comet Helley, J. Geophys. Res., 94, 9983, 1989 c

Contes. A.J., B. Wilken. A.D. John stone. K. Jockers, H.-H Glassmeier, and D.E. Huddleston, Bult properties and velocity distributions of water group ions at comet Halley: Giollo measurements, Geophys. Res., 95, 1990.

Creven, J.D. and L.A. Frank, Alomic hydrogen production rates for comet P/Halley from observations
Atron. Astrophys.. 187, 351, 1987.

Ge Giacobini-Zinner, Geophys. Res. Leti., 13, 275, 1986. Cravens. T.E., The physics of the comeury contuct surface, in: Proc. of 20 th ESLAB Sympasium on the Exploration of Halley's Comet. edited by B. Baturick, EJ. Rolfe and R. Reinhard, Vol. 1, pp. 241, ESA SP-250, Heidelberg. Federal Republic of Germany, 19866 . Cravens, T.E. Ion energetics in the inner come of comet Halley, Geophys. Res. Lett., 14, 983, 1987.

Cravens, T.E., Theory and obvervations of cometary icnospheres, Adv. Space Res., 7, 147, 1987

Cravens, T.E., Comelary plasma boundaries, Adt. Space Res., 9.293,

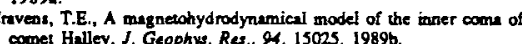
comer Halley, J. Geophys. Res., 94. 15025 19896.

Cravens, T.E., The rolar wind intenction with non magnetic bodies
and the role of smull scale structures, in Solar System Plasma 
Physics, ediled by J.H. Waite, J.L. Burch and T.E. Moore, pp. 353. AGU. Wustington, D.C., $1989 \mathrm{C}$

Cnvens, T.E., Test particle calculations of pick-up ions in the vicinity Co comet Giscobini-Zinner, Planet. Space SCh., 37, I169, 1989d. Cnvens, T.E., Collisional proceses in cometury plasmas, in Cometary
Playme Processes, edited by A.D. Johrstone and A.J. Contes, pp. AGU, Wuhington, D.C., 1990.

Cravens, T.E., Plasma processes in ther inner coma, in Comets in the ost-Halley Era, edited by R.L. Newt

Creven, T.E. Juw. J. Kozyn, A.F. Negy, T.I. Gombori, and M. Kurce Res.ron imped ionizad $7341,1987$.

Cunis, C.C., C.Y. Fan, K.C. Hsich, D.M. Hunten, W.-H. Ip, F Keppler, A.K Richter, G. Umlsuft, V.V. Afonin, A.V. Dyachkov, I Ero, and A.J. Somogyi, Comet P/Halley neutral gas density profite long the Vega-1 trajectory mensured by the Neutzal Gas Experiment,

Ution, C., R. H., A. Souveud, C.W. Cartson, K.A. Anderson, D.W. Curris, R.P. Lin, A. Korth, and D.A. Mendis, Propertits of plasm electrons in the magneuc pite-up region of comel Haley, $A x A$.

Enshkovich, A.L., W.I. Axford, W.-H. L, and K.R. Flemmer, Strbility of the cometury ionopause, Adv. Spacide Res ionopuse survecure, J. Geophys. Res.. 93, 1759, 1988.

Evisur, A., R. Goldstein, D.T. Young. H. Balsiger, H. Rosenbaver, and S.A. Fuselier, Energetic ion fluxes in the inner coms of come P/Halley, Astrophys. J., 339, 545, 1989.

Fedder, J.A., J.G. Lyon, end J.L Giuliani, Numerical simulations of cornets: Predicici.

Fammer, K.R. The globul ineraction of comes with the solst wind in Comets in the Post Helley Era. edited by R.L. Newbum, M. Neugebaver and J. Rahe, pp. Kluwer, New Yort, 1990

Flammer, K.R. D.A. Mendis. T.G. Northrop. und E.C. Whipple. A selfconsistent model for the perticies and felds in the environment of weakly curgessing comer. J. Geophys. Res., 19902.

discontinuity. Application to the cometary ionopeuse, Geophys Res. Lett., $1990 \mathrm{~b}$.

Freund, H.P., and C.S. Wu, Subitity of a spherical shell dinribution of pictup ions, J. Geophys. Res., 93, 14277, 1988.

Fuselies, S.A. K.A. Anderson, H. Baltiger, K.H. Glessmeies, B.E Goldstein, M. Neugebsver, H. Rosenbruer, and E.G. Shelley, The forestock region upstreem from the comet Halley bow shock, ia:
Proc. of SYmposinm on the Diversity ond Similarity of Comets.
edited by E.J. Rolfe and B. Buttrick, Vol. Pp. 7. ESA SP-278, Brussels. Belgium, 1987.

Fusclier, S.A., E.G. Shelley, H. Balsiger, J. Geiss, B.E. Goidstein, R. Goldscein, and W.-H. Ip, Cometary $\mathrm{H}_{2}^{+}$and soler wind $\mathrm{He}^{25}$ dynarnics across the Halley comelopause, Geophys. Res. Leth, 15, 549, 1988,
Gaffey, J., J.D., D. Winske, and C.S. Wu. Time scales for formacio and spreading of velocity shells of pickup ions in the solar wind, $J$. Geophys. Res.. 93. 5470. 1988.

creat. and Continuousiy

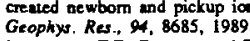

Galever, A.A.A. T.E. Crevens, and TI Gomboti, Solar wind stagnerion seat comes, Astrophys. J., 289. 807. 1985

Galeev, A.A., K.I. Gringauz, S.I. Klimov, A.P. Remizov, R.Z Sagdeev, S.P. Savin, A.Y. Sokolov, M.I. Verigin, K. Szego, M. Thrsallyay, R. Gratd, E.G. Eroshenko, M. Mogilevskii, W. Riedler, and $\mathbf{X}$. Schwingenschuh, Physical processes in the vicinity of the cometopause interpreted on the basis of plasma, magnetic field, and
pinma wrae dats measured on boord the Vega 2 spacecrafi, $J$. pinama wroe data measured on
Geophys. Res., $93,7527,1988$.

Galeev, A.A. and R.Z Sagdeev, Aifven waves in a pace piacme and is rois in the solsr wind isieraction with comets, Astrophys. Space

Gan. L. and T.E. Crevens, Electron energetics in the inner corns of comes Halley, J. Geophys. Res., 95, 6285, 1990.

Gary, P.S., Ind D. Schriver, The elearomagnetic ion cyciotron beam
anisodropy instability, Planet. Space Sci., 35, 51, 1987. Gary. S.P., Electromagnetic ion/ion instabilities and their conrequences in space plasmas: A review, Space Sci. Rev., 1990.
Gary, S.P., K. Akimoto, and D. Winske, Computer simulations of cometary-ion/ion instubilities and wave growth, $J$. Geophys. Res.

Gary, S.P., and C.D. Madland, Electromagnetic ion instabilities in cornetary environment, J. Geophys. Res., 93, 235, 1988.

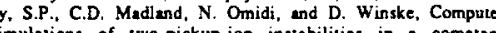
simulations of two-pickup-ion instabilities
envitcriment. J. Geophys. Res., 93, 9584, 1988.

Gany. S.P., and N. Omidi, The ion-ion acoustic instubility, J. Plarme Gary, S.P. and R. Sinis, cometary ion velocity shell distributions, $J$ Geophys. Res from $9131,1989$.

Giusmeier, K.H., A.J. Contes, M.H. Acuna, M.L Goldntein, A.D. Johrstone, F.M. Neubaves, and $H$. Reme, Specinal characteristics of

bow.frequency plasm turtulence upstream of comet Pftalley. I
Geophys. Res., 94. $37,1989$.
Glassmeier, K.H., F.M. Neubauer, M.H. Acuna, and F. Mariani, Low. Glarsmeier, K.H., F.M. Neubaver, M.H. Acana, and F. Mariani, Low
frequency magnetic field fluctuations in comet P/Halley's irequency magnetic field fluctuations in comet P/Halley,
magnetosheach: Gioto observations, Astron. Astrophys., 187, 65, 1987.

Glassmeier, K.H., F.M. Neubuuer, M.H. Acuna, and F. Mariani, Strong hydromagnetic fluctuations in the comet P/Halley magnetosphere. Assron, Astrophys. 187, 65, 19876.

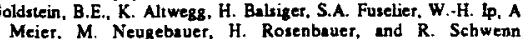
Obrervations of a shock and a recombination layer at the contaci surface of comer Halley, J. Geophys. Res., 24, 17251, 1989.

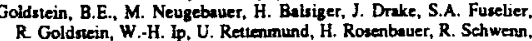
R. Goldsein, W.-H. Ip. U. Retiennund, H. Rosenbever, R. Sehwenn. and E.G. Shelley. Gioto-IMS observations of ion-flow velocities and lemperatures outside the migneic
Astron. Astrophys., 187, 174, 19872.

Goldstein, M.L., D.A. Robers, and W.H. Matthaeus. Numerical amulation of the generation of turtulence from cometary ion pickup. Geophys. Res. Lett., 14, 860, 19876.

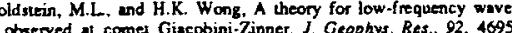
1987.

Goldrtein, M.L., H.K. Worg, and K.H. Glassmeier, Generation of low
frequency waves at comer Halley, J. Geophys. Res., 95, 947, 1990.
Goldstein, R. D.T. Young. H. Balsiger, F. Buchter, B.E. Goldssein, M. Neugebaver, H. Rovenbaver, R. Schwenn, and E.G. Shelley, Ha ions conerved by the Giowo ion mass spectrometer at the

Gombosi, T.I. Charge exchange avalanche at the cometopause, Geophys. Res. Lett., 14. 1174, 1987

Gombosi, T.I. Preshock region accelernion of implamed cometary $\mathrm{H}^{+}$ and $\mathrm{O}^{+}, J$. Geophys. Res., 93, 35, 1988,

ambosi, T.I., Second order Fermi acoeleartion of implanted cometary ions, in Cometary and Solar Plasma Physics, ediled by B. Buti, pp. Worid Scientific, New York, 1988

Gombon, T.I., K. Lorencz, and J.R. Jokipii, Combined firt and Gocond order Fermi accelention at comeds, Adv. Spact Res., 1988. second order Femi accelesation in cometsry convironments, Geophys. Res., 94, 15011, 1989.

Gombosi, T.I., M. Neugebever, A.D. Johstone, AJ. Coater, and D.E Huddleston, Comparison of observed and calcujed impingued ion 1990.

Grard. R. F. Scarf, J.G. Trotignon, and M. Mogilevily, A comparieon between wove observations performed in the envizonmeats of comess Halley and Giacobini-Zinner, in: Proc. of Symposium on the Diversity and Sinilarity of Comels, edived by EI. Rolfe
Busurick, Vol. pp. 97, ESA SP-278, Bnssels. Belgium, 1987.

Gribou, B E K Kecakemety RZ Stgdeev, V.D. Shapino VI Shevchenko, AJ. Somogyi, K Szego, G. Erdsi, E.G. Erosbenko, Richter, W. Riedler, K. Schwingenschuh, and K.P. Wenzel, Siochaslic Fermi acceleration of ions in the pre-shock region of Siochaslic Fermi acceleration of ions in the pre-shock
comet P/Halley. Astron. Astrophys., 187, 293, 1987.

Gringsuz, K.I., T.L. Gombosi. A.P. Remizov, I. Apsthy, L Szemercy, M.I. Verigin, L.I. Denchikova, A.V. Dyachkov, E. Kepples, I.N. Klimenko, A.K. Richter, A.J. Somogyi, K. Szegö, S. Szendro, M. Therallyay, A. Verge. and G.A. Vladimirova, First in size plasme and neutral gas measurements at comet Halley, Netwre, 321, 282, 1986e.
Gringauz, K.I. T.I. Gomboti, M. Tfirallyay, M.I. Verigin, A.P. Remizov, A.K. Richter, I. Apsithy, I. Szemerzy. A.V. Dyachkov, O.V. Belakina, and A.F. Nagy, VECA observations of the cometopause

Gringauz, K.I., and M.1. Verigin, Nonstationary phenomens in the hesd of comer P/Halley, in Cometary Plasme Processes, edied

A.J.C. A.D. Johnstone, pp. AGU, Washington, D.C., 1990

Gurgolo, $C_{\text {., }}$ and J.D. Winningham, lon acceleration at the contact
surfoce of comes P/Halley, I. Geophys. Res., 95, 17051, 1990.

Heerendel, G.. Plasma uransport near the magnetic cavisy surrounding

comer Halley. Geophys. Res. Lett., 14, 673, 1987.

Hizanidis, K. P.J. Cargill, and K. Papadopoujos. Lower hybrid waves upstream of comets and their implications for the comes Halley "bow wive", J. Geophys. Res., 93, 9577, 1988.

Hsieh, K.C., C.C. Curtis, C.Y. Fan, D.M. Hunten, W.-H. Ip, E. Keppler, A.K. Richter, G. Umlauft, V.V. Afonin, J. Ero, and A.J. Somogyi, Anisotropy of the neutral gas distribution of comet
P/Halley deduced from NGE/Nega 1 mensurements, Astron.

Astrophys., 187. $375,1987$.
Huebner, W.F., D.C. Boice, H.U. Schmidt, M. Schmidt-Voigt, R.

Wegmann, F.M. Neubuuet, und J.A. Slavin, Time-dependent study of magnetic fields in com

Hynds, R.J., S.W.H. Cowley, T.R. Sanderson, K.P. Wenzel, and J.J. Ven Rooijen, Observations of energetic ions from comer GincobiniZinner, Science, 232, 361, 1986.

Ip. W, -H., On charge exchange effect in the vicinity of the cometopeuse of comea Halley, Astrophys. J., 343, 946, 1989.
ip, W.-H., Energetic neutral atoms in comesary comas, Astrophys. J., $353,290,1990$

Ip. W.H., R. Schwenn, H. Rosenbaver, H. Balsiger, M. Neugebeser, and E.G. Sheiley, An interpretation of the ion pise-up region oulside
the ionospheric contact surface, Astron. Asirophys., 187, 132,

lp. W.H., and W.I. Axford, The scceleration of particles in the vicinity Ipuvich, F.M. A.B. Gaivin, G. Gloeckler, D. Hovesudk, B. Klecker, and $M$. Scholes, Comet Giacobini-Zimner: In situ observacions of energevic heivy ions, Science, 232, 366, 1986,

Isenberg. P.A., Energy diffusion of pickup ions upstresan of coseness. $J$ Geophys. Res., 92, 8795, 1987.

Isenberg. P.A., Evolution of intersertar pickup ions in the rolas wind, J. Geophys. Res., 92, 1067, 19876. Isenberg. P.A., Comment on "Slochaztic acceleration of cometary
pickup ions: The clasic leaky box model" by D.D. Barboss.
Astrophys. J. 1990.

Astrophys. J. 1990.
Jockers, K. The ion wil of comer Kohoulet 1973XII during 17 days of solar wind guss, Astron. Astrophys. Suppl.. 62, 791, 1985.

Kaya, N. H. Massumolo, end B.T. Tsuruteni, Test particle simulation of whister wave peckets observed
Geophys. Res. Lett., 16, 25, 1989 .

Kecikemety, X., T.E. Cravens, V.V. Afonin. G. Endor, E.G Erosheniko, L. Gan, T.I Gombosi, K.I Gringave, E. Keppler, iN. Klimesko, R. Marxden, A.F. Nagy, A.P. Remizoy, A.K. Richter, W. Riedlet, K. Schwingenschuth. AJ. Samogyi, M. Thitrillyay, A.

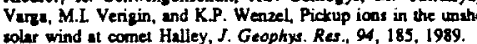

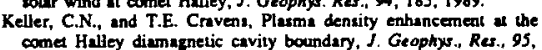
comet Halley dist 1990

Kellogg. P.J., Influence of instabilities on plesma flow around a comel, J. Geophys. Res., 94, 15, 1989.

mmel. C.D.. J.G. Luhmann. J.L. Phillips, and J.A. Fedder. Chancteristics of cometary picked-up ions in a globs
Giacobini-Zinner, J. Geophys. Res.. 92. 8536. 1987.

Kö̈me, H. H. Motsuro Y Y Omur. and B.T Tsuruini Nonlinear evolution of high frequency $R$-mode waves excited by water group
ions near comes: Computer experiments, Geophys. Res. Letl., 16 . ions near 1989.

Körösmezey, A., T.E. Cravens, T.I. Gomboni, A.F. Nagy, D.A.

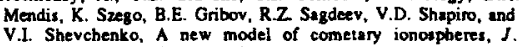
Geophys. Res., 92, 7331, 1987.

Korth, A., A.K. Richter, D.A. Mendis, K A Andereon, C. W Cartson D.W. Cuntis, R.P. Lin, D.L. Mitchell, H. Reme, J.A. Sauveud, and C dUston, The composition end ndial dependence of cometary ions in

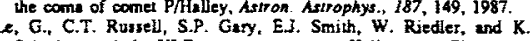
Schwingenschuh, ULF waves at comest Hailey and Giscobini-
$11989,1989$.

Le. G., C.T. Russell. S.P. Gary, E.J. Smith, W. Riedler, and K Schwingenschuh. ULF waves at comets Halley and GiscobiniZinner: comparison with theory, Adv. Space Res. 9, 373, 1989b. from the Earth and comets, Adv. Space Res., 9, 363, 1989c. Le, G., C.T. Russell, and E.I. Smith, Discrete wave, packets upetream from the Earth and comets, J. Geophys. Res, 94, 3755, 1989d.
Lee, M.A., ULF woves at comets, in Plasma Waves and Instabilities Comets and Magnelospheres, in Plited by B.T. Truntenni and H. Oya, PP. 13, American Geophysical Union, Washington, D.C.. 1989. A. A

Lee, M.A., and W..H. Mp, Hydromanentic wave excilation by ionized interntellar hydrogen and
Res., $92,11041,1987$.

Luhmann, J.G., J.A. Fedder, and D. Winske, A lest paricle model of

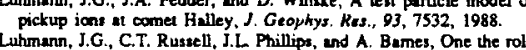
of the quasi-panillel shock in ion piciup: A lesson from Venus?, $J$.

Melart, F., G. Einaudi, and A. Margeney, A quesi-one-dimensional model for the Giecobini.Zinner plasma wil, J. Geophys. Res., 94,

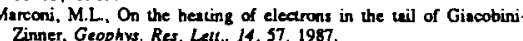
Zinner, Geophys. Res. Latt. 14, 57, 1987.
MeComas, DJ., IT. Gosling. S.J. Bame. J.A. Stavis, E.J. Smith, and J.L. Steinberg. The Giscobini-Zinner magnetotail: Tril McComas, D.J., J.T. Gosling. C.T. Russell, and J.A. Slavin, Magnetouilis at unmagnetized bodies: Comparison of comet
Giscobini-Zinner and Venus, J. Geophys. Res., 92, 10111,19876 . McKenna-Lewlor, S., P. Daty, E. Kirsch, B. Wilken, D. O'Sullivan, A. Thompwon, K. Kecskeméty, A. Somogyi, and A. Costes, In situ energetic particle observations at comet Halley recorded by
instrumentution aboard the Giono and Vega 1 missions, Annales

McKeophasicae, T, 'S., E. Kirsch, D. OS Sulliven, A. Thompson, and K. P. Wenzel, Energetic ions in the environment of comet Helley,

Mendis. D.A. Interaction of comets with the woler wind and sole ndistion, in Cometary and Solay Plasm
pp. Wortd Scientific. New Yort. 1988.

Mendis, D.A., K.R. Flemmer, H. Reme, J.A. Seuveud, C. D'Usion, E. Cotin, A. Cros, K.A. Andenon, C.W. Carison, D.W. Cuntis, D.E Laron, R.P. Lin, F.L. Mitchell, A. Konh, and A.K. Richter, On the global nature of the solar wind intenction with conet Halley, Ann.

Mendis, D.A., H.L.F. Houpis, and M.L Marconi, The phytics of comeis, Fund. Casmic Phys., 10, 1, 1985

cendis, D.A., EJ. Smith, B.T. Tsurutani, J.A. Slavin, D.E. Jones, and G.L Siscoe, Comet-solut wind internction: Dynn
and models, Geophys. Res. Lest., 13, 239, 1986.

Meyer-Vermet, N., P. Couturier, S. Hoang, C. Perche, J.L Steinberg. J. Fainberg, and C. Meetre, Plasma disgnosis from thermal noise and 232, 370, 1986.

Miller, R.H., T.I. Gombosi, S.P. Gary, and D. Winske, Directiona dependence of magnetic field fuctualions in the quasi-panallel and Adv. Space Res., 1990a.

Miller, R.H., T.I. Gombosi, S.P. Gary, and D. Winske, The directiona dependence of magnetic fluctuasions generated by cometary io pick-t2p, J. Geophys. Res, 19906.

Morison, P.J., and D.A. Mendis, On the fune structure of cometar plasma tails, Astrophys. J., 226, 350, 1978.

Nagy, A.F., Photochemistry of pienewary jonospheres, Adv. Space

Neubauer. F.M., The ionopause transition and boundary layers at come
Halley from Gioto magnetic field observations, J. Geophys. Res. 93. 7272, 1988

Neubsuer, F.M.. K.H. Glessmeier, M. Potl, J. Rueder, M.H. Acura, LF. Burlaga, N.F. Ness, G. Musmann. F. Marieni, M.K. Wallis, E. Ungssrup, and H.U. Schmidt, First resulss from the Giotto magnecometer experiment at comet Halley, Nature, 321, 352, 1986. Neugebauer, M., Spacecraft observations of the interaction of active comets with the solst wind, Rev. Geophys., 28, 231, 1990.
eugebsuer, M. A.J. Contes, und F.M. Neubaver, Comparison of peugebauer, M., A.J. Coates, end F.M. Neubauer, Comparison of
picked-up protons and water group ions upsiream of comet Halley's Dow shock, J Geophys Res 95, $18745,1990$.

Neugebuver, M., B.E. Goldstein, H. Balsiger, F.M. Neubauer, R Schwenn, and E.G. Shelley, The density of comelary protons
upstream of cornet Halley's bow shock, J. Geophys. Res., 94,1261 ,

Neugebaver, M., R. Goldstein, B.E. Goldstein, S.A. Fuselier, H. Balsiger, and W.-H. Ip. Densitiez and sbundances of hot comelary ions in the coma of comet Haley, Astrophys. J. 1990. R. Goldstein, A.J. Lezanus, K. Alweeq. H. Balsiger, B.E. Goldstein. Shelley, end E. Ungstrup. The pickup of corretsing protons by the solar wind, Asiron. Astrophys., 187, 21, 1987.

eugebsuer, M. A.I. Lezanus, H. Bulsiger, S.A. Fuselier, F.M. Neubauer, and $H$. Rosenbauer, The velocity distriburions of comerary
procons picked up by the solar wind, $J$. Geophys. Res., 24,5227 , Neubaus.
proxons
1989.

Neugebauer, M., F.M. Neubauer, H. Balsiger, S. Fuselier, B.E. Goldstein, R. Goldstein, F. Mariani, H. Rosenbuer, R. Schwenn thistion of protons, alphas parricles, and the magnetic field across

Niedner. M.B., and J.C. Bnndt, Plesms cail disconnection events in comets: Evidence for magnetic field line reconnection a Niedner. M.B., and X. Schwingenschuh, Plasma-tail dectivity at the

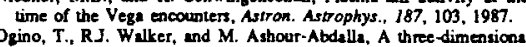
Ozino, T., RJ. Walker, and M. Ashour-Abdalla, A three-dimensional
MHD simulation of the interaction of the solnt wind with comet MHD simulation of the interaction of the

Halley, J. Geophys. Res., 93, 9568, 1988.
Omidi, N., and D. Winske. A kinetis surdy of solar wind mass loeding and cometary bow thocks, J. Geophys. Res., 92, 13409, 1987. of planesary bow shocks and al comet Gincobini-Zinser, Geophys. 15, 1303, 1988

into $N$., and D. Winzke, Steepening of kinetic magnetoronic waves and cometh, J. Geophys. Res., 95.2281 , 1999 .

Omidi, N., and D. Winske. Theory and simulation of cornetury thocks, 
in Comesary Plasma Processes, edited by A.D. Johnstone and A. Contes, pp. AGU, Washington, D.C., 1990

Omidi, N., D. Winske, and K.B. Quent, The effect of iontaeural collisiont on the structure of electrostatic shocks: Appliculion to cornethry inner shocks, Eos, 70, 384, 1989

Omidi, N., D. Winske, and C.S. Wu. The effect of heavy ions on the fortantion and structure of cometary bow shocks, Icarus, 66, 165,

Perez-de-Tejada. H., Viscous flow interpreution of comet Halley's myntery trunsition, J. Geophys. Res., 94. 10131. 1989.

Price. C.P.. Mirror waves driven by newbom ion distributions, $J$ Geophys. Res., 24, 15001, 1989.

Pnce, CP. J.D. Gaffey, and J.Q. Dong. Exciencion of low-frequency hydromagnetic waves by freshily

Price, C.P., and L.C. Lee, Comel-wolar wind interaction through ion pmoton beem instability, Astrophys. J., 324, 606, 1988

Price, C.P., and C.S. Wu, The influence of strong hydromagnevic turbulence on newbom cometury ions, Geophys. Res. Lett., 14

Reder, S., F.M. Neubaver, N.F. Ness, and L.F. Burhaga, Macroscopic perurbations of the LMF by P/tatiey as seen by the Giors magnetometer, Astron. Astrophys., 187, 61, 1987

(n) contect and AJ. Coules, pp. AGU, Washington, D. C. 1990

and AJ. Coster, pp. AGU, Washington, D.C.. 1990. Gorlion, D.W. Cursis, R.P. Lin, A. Konth, A.K. Richier, and D.A Mendis, General fentures of comet P/Halley: Soler wind intenation from plasms mensurements, Astron. Astrophys., 187, 33, 1987.

Richardson, I.G., S.W.H. Cowley, K.-P. Wenzel, F.L. Scarf, E. Srmilh, B.T. Tsurutani, T.R. Sanderion, and R.J. Hynds, Plasm wave, magnetic field and energetic ion observations in the ion pick up regi.

Richardson, I.G., R.-P. Wenzel, S.W.H. Cowley, F.L. Sarf, E. Smich, B.T. Trurukeni, T.R. Sunderion, and R.S. Hynds, Comelared plans wove, magnetic field, and energetic ion observations in the 49. 1989 b.

Russel1, C.T., The interaction of the solar wind with comet Halley: Upwind and downwind, Q. J.R. Astron. Soc., 29, 157, 1988.

Russell, C.T., L. Guan, J.G. Luhmann, and J.A. Fedder. The visual appearance of comets under varying soler wind conditions. Ady. Space Res., 9, 393, 1989.

Russeli, C.T., J.G. Luhman, and D.N. Baker, An examination of ponsibie solur wind sources for a sudden brighrening of comet IRAS ARAKI-ALCOCK: Geophys, Res. Lett., 14, 991, 1987

Russell, C.T., W. Riedler, K. Schwingenschuh, and Y. Yeroshenko, Mirror insubility in the magneworphere of comet Halley. Geophys. Res. Latt., 14, 644, 1987b.

mell, C.T., M.A. Saunders, J.L. Phillips, and J.A. Fedder, Near toij reconnection as the cause of
Geophys. Res., $91,1417,1986$.

Sagdeev, R.Z, V.D. Shapiro, V.L. Shevchenko, and K. Szezó, MHD wrtalence in the solar wind - comet internetion region, Geophys. mirtulence in the soler wind
Res. Lett., 13. 85, 1986.

Sewer, K., U. Mosuchmamn, and T. Raeuch, Plauma bounderies at comes Halley, Ann. Gsophys., 8. 243, 1990

Scarf. F., Plasms physics phetiomens derected at comet Giacotin Zimner, in Comelary and Solar Plasma Physics, edited by B. Buti. p. World Scientific, New York, 1988.

Scarf. F., Plasma wave observations at comets Giacobini-Zinner ond Halley, in Plasme Waves and Instabilities at Comess and Maznelospheres, edited by B.T. Tsurutani and H. Oya, pp. 31 , American Goophysical Unjon, Washington, D.C., 1989.

Carf, F.L, F.V. Coronit, C.F. Kennel, W.H. D, D.A. Gurnet, and

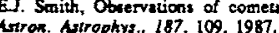

Schwena, R., W..H. Ip. H. Rocenbatuer, H. Balsiger, F. Buhles R

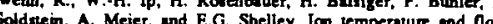
profiles in comet $P / H$ alley's close environment, Asiros. Astropkys., 187, 160. 1987.
J.G. Luhmenn, C.T. Russell, J.A. Fedder, A. Somogri, and $Y$. Yeroshenko, Varisbility of comet Halley's coma: Vegn-1 und Vega2 magnetic field observations, in: Proc. of Symposium on the Diversity and Similarity of Comets, edited by E.J. Rolfe and $B$. Buttrick, Vol. pp. 63, ESA SP-278, Brussels, Belgiurn, 1987.

chwingenschuh, K., W. Riedles, Y. Yeroshenko, J.L. Phillips, C.T Russell, J.G. Luhmasn, and J.A. Fedder, Magnetic field draping in the comet Halley coms: Companison of Vege observations with conputer simuiations, Geophys. Res. Lett., 14, 640, 1987.

A. Papadopoulos, Resonance dropption of Alfven waves at comet-

Shelley, E.G., S.A. Fuselier, H. Basisiger, J.F. Drake, J. Geiss, B.E. Goldstein, R. Goidstein, W.-H. Ip. A.J. Lezarus, and M. Neugebauer, Cherge exchange of solar wind cons

Sisvin, J.A., E.J. Smith, B.T. Tsurutuni, G.L. Siscoe, D.E. Jones, and D.A. Mendis, Giscobini-Zinner magnetotoil: Ioc magnetic field observations, Geophys. Res. Lett, 13, 283, 1986.

Somogyi, A.J, K.I. Gringouz. K. Szegó, L. Szabs, G. Kozma, A.P. Remizov, J. Erö Ir., IN. Klimeniso, I.T. Sxǘs, M.I. Verigin, J. Windberg. T.E. Cravens, A. Dyachiow, G. Erdbs, M. Fango, T.I. Gombosi, K. Kecrkeméty, E. Keppler, T. Kovict Jr., A. Kondor. Y.1. Logachev, L Lohonyai, R Manden. R. Redl. A.K. Richter, V.O. Stolpovsikil, J. Szabs, I. Szentpetery. A. Szepesvíry, M. Zirindy, First observations of energetic perticles near comet Halley, Nature, 321, 285, 1986.

Stewarn A.IF., Pioneer Venus measurements of $H, O$, and $C$ production in comet P/Halley near perihelion, Astron. Astrophys, 187,369 1987.

Sydora, R.D., and I. Raeder, A particle MHD simulation approach with applicition to global comet-solst wind interaction model, in Comelary and Solar Plasma Physics, ediced by B. Buti, pp. World
Scientific, New York, 1988.

Twn, L.C., G.M. Maton, G. Gloeckler, F.M. Ipavich, and A.B. Galvin. Energetic heavy ions observed near comet Giscobini-Zinner, $J$.

Thiemann, H., R.W. Schurk, and R. Zwickl, Dymemic PIC-simulations of charging phenomena related to the ice-spacecrntt in both 1989.

A.D. M.F., W. Feldman, B. Wilken, K. Jockers, W. Studemann A.D. Johnstone, A.J. Costes, V. Formiseno, E. Amsin, I.D. observacions of a birnodal ion distribution in the outer come of

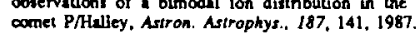

Thome, R.M., and B.T. Trurvitni, Resomant interaclions between comelary ions and low frequency electromagnetic waves, Planel. Space Sci., 35, 1501, 1988

Tourutani, B.T., Comeuny phasma waves and instabilicies, in Comers in the Post-Halley Era, edited by R.L. Newbum, M. Neugebaver and J. Rathe, pp. Kluwer Publishing Company, New York, 1990.

Trurutani, B.T.. Comets: A baborstory for plasma waves and instabilities, in Cometory Plasme Processes, edized by A.D. Tsurntuni, B.T. A.L. Brinca, B. Bui, E.J. Smith, R.M. Thome Muteri, B.T. AL Brica, B. But. E.J. Smith, R.M. Thome, and $\mathrm{H}$ Matsumoto, Magnetic pulses with durntions near the local prowon cyciotron 1989

Tsunteni, B.T. A.L. Brinca, EJ. Smith, R.M. Thome. F.L. Scarf, J.T. Golling, and F.M. Ipuvich. MHD waves detected by ICE as distunces

Atron. Astrophys., 187. 97. 1987.
Taunuen, B.T., D.E. Pege. E.j. Smich, B.E. Galdstein, A.L. Brince R.M. Thome, H. Marsumoro, LG. Richardion, and T.R. Sendernon, Low-frequency plasme wives and ion pitch mgle scaucring at large

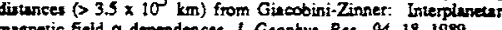
magresic tield a dependences. J. Grophys. Res., $44,18.1989$.

Discrete thace waves: comet Giscobini-Zinner, Geophys. Res. Lell, 17, 1817, 1990.

Tsunsteni, B.T., E.J. Smith, H. Matsumoto, A.L. Brinca and N. Omiti,
Highly nonlinear magnetic pulses at comet Giacobini-Zinner, Geophys. Res. Lett., 17, 757, 1990

Tsuruteni, B.T. R.M. Thome, E.J. Smith, A.L. Brince, and H. Matsumolo, Properties of whistler mode wave packets at ihe leading dge of itcepened magnetosonic waves: Comel Giscobini-Zinner. Planet. Space Sci., 37, 167, 198

Turutuni, B.T., R.M. Thome, E.J. Smith, J.T. Gosling, and H. Messumoto, Steepened magnelosonic waves at comes GinosiniZiner, J. Geophys. Ras., 92, 11074, 1987.

Walliw, M.K., and M. Dryer, Sun and comers at sources in an extema

Wallis, M.K., and R.S.B. Ong. Strongly cooled ionizing plasma flows with applicetions to Venus, Planet. Space Sci., 23, 713, 1975

Wegmann, R. H.U. Schrnidi. W.F. Huebner, and D.C. Boice, Cometar Whipele, FI The sccelertion of comet Encke, Airophys

375, 1950

Winske, D., C.S. Wu, Y.Y. Li, Z.Z Mou, and S.Y. Guo, Coupling of newbom ions to the solat wind by electromagneúc instabilivies and their intenction with the bow shock, J. Goephys. Res., 90, 2713, Wu, C.S., and R.C. Davidson. Electromagnetic instabilities produced by neutral paricle ionization in interplanetary space, J. Geophys.

and C.P. Price, Exciturion of whistlen and waves with mixed polsrization of newbom comelnty ions, $J$. Geophys

Wu, C.S., D. Kreuss-V

us-Varban, and T.S. Huo, A mirror insubility asociated with newly exalc

Wu, C.S and P.F. Yoon, Kinetic hydrom anctic instabilities due to ipherical shell

Ye, G., and T.E. Cravenu, Combined energy and pitch-angle diffusion of pick-up iont at conet Haliey, J. Geophys. Res., 1990

Yoon, P.H., Kinetic insubility sssocialed with = spherical shell distribution of cometsry pickup ions, Geophys. Res. Letl., 17,

Yoon, P.H., M.E. Mandt, and C.S. Wu, Evolution of an unstable shell distribution of pickup cometary ions, Geophys. Res. Lett., 16 , 147.

Pand particle internations, in Comets in the Post-Helley Era, edited by
J.R.L. Newbum, M. Neugebeuer and 3. Rahe, pp. Doritechl, the Neiherlands, 1990

Yoon, P.H., and L.F. Ziebell, Deveiopment of pitch-angle anisoropy and velocity diffusion of pickup ion thell distributions by sole wind turbulence, J. Geophys. Res., 95. 17085, 1990.

Yoon, P.H., L.F. Ziebell. and C.S. Wu, Self-consistent pitch-engle Ziebell. LF., and P.H. Yoon, Pitch angle and velocity diffurion of newbom ions by turbulence in the sols wind, J. Geophys. Res., 95 ,

Ziebell, L.F., and P.H. Yoon, Pitch-angle and velocity diffusion of $1990 \mathrm{~b}$.

Zelell, L. P.H. Yoon C.S Wu and D. Winske, Pitch ang diffusion of diffusion of newbom ions by intning,
J. Geophys. Res., 95, 17075, 1990

T. I Gombosi, Department of Atmospheric, Oceanic and Space Sciences, Space Physics Research Laboratory, University of Michigen. 2455 Hayward, Ann Arbor, MI 48109-2143.

(Received September 24, 1900 revised January 22, 1991; accepted January 22, 1991.) 